\title{
Relationship of hyperuricemia with metabolic alterations and cardiovascular risk factors in a population of Mexican young adults
}

\author{
Ashuin Kammar-García*, Patricia López-Moreno, María Elena Blásquez-Gutiérrez, \\ María Elena Hernández-Hernández, Angélica María Ortiz-Bueno and \\ María de Lurdez Consuelo Martínez-Montaño \\ Benemérita Universidad Autónoma de Puebla, Department of Biochemistry, Puebla, Puebla, Mexico
}

\begin{abstract}
Introduction: Hyperuricemia is a risk factor for cardiovascular disease, but its impact has not been properly documented. Objective: To assess the impact of hyperuricemia on metabolic parameters and cardiovascular risk factors (CRF) in apparently healthy Mexicans. Method: Cross-sectional study of 768 young adults. Association of hyperuricemia with alterations in metabolic parameters and CRF (hypertension, mixed dyslipidemia, metabolic syndrome) was sought. Log-linear and regression models were used to determine the influence of hyperuricemia. A multivariate analysis of variance was applied to observe the interaction of hyperuricemia and overweight or obesity with changes in metabolic parameters. Results: Metabolic parameters were higher in patients with hyperuricemia than with normal uric acid (all $<0.05)$. Hyperuricemia was significantly associated with hypertension (OR =6.8, $95 \% \mathrm{Cl}$ : 1.1-46), dyslipidemia (OR=2.5, 95\% Cl: 1.3-4.7) and metabolic syndrome (OR=2.3, 95\% Cl: 1.1-4.6). Hyperuricemia and overweight or obesity significantly predict changes in cardiovascular risk metabolic parameters (Wilks' $\lambda=0.91, F(6.175)=3.1, p=0.007$ ). Conclusions: Hyperuricemia is significantly associated with metabolic alterations and different CRF.
\end{abstract}

KEY WORDS: Uric acid. Cardiovascular risk. Hypertension. Dyslipidemia. Metabolic syndrome.

\section{Introduction}

Among the 10 leading causes of death in the world, cardiovascular diseases (CVD), such as ischemic heart disease and stroke, which cause more than 15 million annual deaths, have remained the main cause of death over the last 15 years. ${ }^{1}$ In Mexico, CVD caused more than 135,000 deaths in 2016 and currently it is regarded as the leading cause of death in the country. ${ }^{2}$ Therefore, the search for different markers associated with the risk of CVD has been crucial. One of these markers is uric acid (UA), an end-product of the metabolism of endogenous purines and of those consumed in the diet. $^{3}$ Hyperuricemia can be defined as the presence of UA serum values $>6$ or $7 \mathrm{mg} / \mathrm{dL}$ in women and men, respectively. ${ }^{4}$ This clinical entity is common in individuals with CVD, ${ }^{5}$ but has also been associated with cardiovascular risk factors such as hypertension, ${ }^{6}$ obesity, ${ }^{7}$ metabolic syndrome, ${ }^{8}$ insulin resistance, ${ }^{9}$ dyslipidemia ${ }^{10}$ and atherogenic indices. ${ }^{11}$ It is important noting that most studies that assess the relationship of hyperuricemia with metabolic parameters or cardiovascular risk factors have been carried out in specific populations with high risk for CVD, such as middle-aged adults or older adults, postmenopausal women, patients with kidney disease or with a history of CVD. Although analyses have been carried out in populations of children and adolescents, young adults aged between 18 and 22 years have not
Correspondence:

*Ashuin Kammar-García

E-mail: kammar_nutrition@ hotmail.com
Date of reception: 02-11-2018

Date of acceptance: 15-02-2019

DOI: 10.24875/GMM.19004811
Gac Med Mex. 2019;155:217-222

Contents available at PubMed www.gacetamedicademexico.com 
Table 1. Comparison of clinical characteristics, metabolic parameters and cardiovascular risk factors in individuals with and without hyperuricemia

\begin{tabular}{|c|c|c|c|c|c|c|c|}
\hline \multirow[t]{2}{*}{ Variable } & \multicolumn{2}{|c|}{$\begin{array}{l}\text { Total } \\
(n=768\end{array}$} & \multicolumn{2}{|c|}{$\begin{array}{l}\text { Normal uric acid } \\
\quad(n=579)\end{array}$} & \multicolumn{2}{|c|}{$\begin{array}{l}\text { Hyperuricemia } \\
\text { (n= } 189\end{array}$} & \multirow[t]{2}{*}{ p } \\
\hline & \multicolumn{2}{|c|}{ Mean \pm SD } & \multicolumn{2}{|c|}{ Mean \pm SD } & \multicolumn{2}{|c|}{ Mean \pm SD } & \\
\hline Age (years) & \multicolumn{2}{|c|}{$18.8 \pm 1.4$} & \multicolumn{2}{|c|}{$18.8 \pm 1.4$} & \multicolumn{2}{|c|}{$18.8 \pm 1.3$} & 0.7 \\
\hline Weight (kg) & \multicolumn{2}{|c|}{$63.9 \pm 13.5$} & \multicolumn{2}{|c|}{$62.2 \pm 12.5$} & \multicolumn{2}{|c|}{$69.1 \pm 15.1$} & $<0.0001$ \\
\hline Height (m) & \multicolumn{2}{|c|}{$1.66 \pm 0.56$} & \multicolumn{2}{|c|}{$1.66 \pm 0.64$} & \multicolumn{2}{|c|}{$1.66 \pm 0.08$} & 0.9 \\
\hline Waist (cm) & \multicolumn{2}{|c|}{$82.6 \pm 10.8$} & \multicolumn{2}{|c|}{$81.4 \pm 9.8$} & \multicolumn{2}{|c|}{$86.2 \pm 12.7$} & $<0.0001$ \\
\hline BMI & \multicolumn{2}{|c|}{$23.6 \pm 4.4$} & \multicolumn{2}{|c|}{$23.2 \pm 3.7$} & \multicolumn{2}{|c|}{$25.1 \pm 5.7$} & $<0.0001$ \\
\hline Glucose (mg/dL) & \multicolumn{2}{|c|}{$88.5 \pm 16.8$} & \multicolumn{2}{|c|}{$87.9 \pm 17.5$} & \multicolumn{2}{|c|}{$90 \pm 14.2$} & 0.1 \\
\hline Total cholesterol (mg/dL) & \multicolumn{2}{|c|}{$165.3 \pm 29.6$} & \multicolumn{2}{|c|}{$163.1 \pm 28.9$} & \multicolumn{2}{|c|}{$171.9 \pm 30.6$} & $<0.0001$ \\
\hline Triglycerides (mg/dL) & \multicolumn{2}{|c|}{$116.2 \pm 54.4$} & \multicolumn{2}{|c|}{$110.4 \pm 50.2$} & 134 & 2.5 & $<0.0001$ \\
\hline HDL-C (mg/dL) & 49.5 & & 50.3 & & 47. & & 0.003 \\
\hline LDL-C (mg/dL) & 92.6 & & 90.8 & & & & 0.001 \\
\hline VLDL-C (mg/dL) & 22.9 & & 21.9 & & $26 . \varsigma$ & & 0.005 \\
\hline SBP (mm Hg) & 115. & & 113. & & 121. & 2.7 & 0.001 \\
\hline DBP (mm Hg) & 70. & & 69.8 & & & & 0.003 \\
\hline & $\mathrm{n}$ & $\%$ & $\mathrm{n}$ & $\%$ & n & $\%$ & \\
\hline Women/men & $466 / 302$ & $61 / 39$ & $380 / 199$ & $66 / 34$ & $86 / 103$ & $46 / 55$ & $<0.0001$ \\
\hline Abdominal adiposity & 126 & 16.5 & 85 & 14.6 & 42 & 22 & 0.04 \\
\hline Overweight or obesity & 237 & 30.9 & 154 & 26.6 & 83 & 43.9 & $<0.0001$ \\
\hline Hyperglycemia & 20 & 2.6 & 10 & 1.7 & 10 & 5.3 & 0.01 \\
\hline Hypercholesterolemia & 92 & 12 & 58 & 10 & 34 & 18 & 0.003 \\
\hline Hypertriglyceridemia & 157 & 20.4 & 102 & 17.6 & 55 & 29.1 & 0.001 \\
\hline Low HDL-C & 295 & 38.5 & 207 & 35.8 & 88 & 46.6 & 0.006 \\
\hline High LDL-C & 175 & 22.8 & 117 & 20.2 & 58 & 30.7 & 0.002 \\
\hline High VLDL-C & 155 & 20.2 & 94 & 16.2 & 65 & 34.6 & 0.006 \\
\hline Hypertension & 25 & 3.3 & 8 & 1.4 & 18 & 9.3 & 0.03 \\
\hline Mixed dyslipidemia & 44 & 5.7 & 23 & 4 & 21 & 11.1 & 0.001 \\
\hline Metabolic syndrome & 37 & 4.8 & 18 & 3.1 & 19 & 10.1 & $<0.0001$ \\
\hline
\end{tabular}

Student's t-test comparison for independent samples in continuous quantitative variables and by chi-square or Fisher's exact test for categorical variables.

$\mathrm{BMI}=$ body mass index, HDL-C = high-density lipoprotein cholesterol, LDL-C = low-density lipoprotein cholesterol, SD = standard deviation, VLDL-C = very low density lipoprotein cholesterol.

been examined. Therefore, the purpose of this research is to assess the impact of hyperuricemia on metabolic parameters and cardiovascular risk factors in apparently healthy young Mexican adults.

\section{Method}

A cross-sectional study was carried out at the Benemérita Universidad Autónoma de Puebla from
August 2011 to May 2018. Mexican individuals aged between 18 and 22 years, without a medical history of metabolic alterations in the previous year, who were not receiving pharmacological treatment for chronic or metabolic diseases or with specific diet were included. Subjects without a fasting period longer than 12 hours, who referred metabolic alterations within the previous year or who decided not to participate were excluded; subjects in whom hemolyzed 
or lipemic serum was obtained were removed from the study.

Individuals attended the facilities of the Benemérita Universidad Autónoma de Puebla Faculty of Medicine Department of Biochemistry, where they underwent somatometry (weight, height and waist circumference), history taking and clinical assessment (blood pressure), with a peripheral blood sample being obtained by venipuncture for biochemical analysis (VITROS DT60 I® analyzer, Ortho-Clinical Diagnostics, Raritan, NJ, United States), which included quantification of glucose, total cholesterol, triglycerides, UA and high (HDL-C), low (LDL-C) and very low density lipoprotein cholesterol (VLDL-C).

Alterations in body composition and metabolic parameters, as well as risk factors were categorized according to the Adult Treatment Panel Guidelines (ATP-III):12

- Waist circumference $\geq 80 \mathrm{~cm}$ in women or $\geq 90 \mathrm{~cm}$ in men, abdominal adiposity.

- Body mass index (BMI) $\geq 25$, overweight or obesity

- Hyperglycemia, fasting serum glucose $\geq 100 \mathrm{mg} / \mathrm{dL}$.

- Hypertriglyceridemia, serum triglycerides (TGL) $\geq 150 \mathrm{mg} / \mathrm{dL}$.

- Hypercholesterolemia, total cholesterol values $\geq 200 \mathrm{mg} / \mathrm{dL}$.

- Decreased HDL-C, $<40 \mathrm{mg} / \mathrm{dL}$ in men or $<50 \mathrm{mg} / \mathrm{dL}$ in women.

- High LDL-C,> $100 \mathrm{mg} / \mathrm{dL}$.

- High VLDL-C, $\geq 30 \mathrm{mg} / \mathrm{dL}$.

- Hyperuricemia, serum UA > 6 and $7 \mathrm{mg} / \mathrm{dL}$ in women and men, respectively.

- Altered systolic blood pressure (SBP), $\geq 130$ $\mathrm{mm} \mathrm{Hg}$.

- Altered diastolic blood pressure (DBP), $\geq 85$ $\mathrm{mm} \mathrm{Hg}$.

- Hypertension, blood pressure values higher than 130/85 mm Hg.

- Dyslipidemia, TGL $\geq 150 \mathrm{mg} / \mathrm{dL}$ and total cholesterol $\geq 200 \mathrm{mg} / \mathrm{dL}$.

- Metabolic syndrome, presence of three or more risk factors according to ATP-III.

The variables are presented as the mean \pm standard deviation and as frequencies and proportions. A normality test was performed by means of the Kolmogorov-Smirnov statistic. Parametric statistics were obtained in the comparison of quantitative continuous variables using Student's t-test. Non-parametric comparisons in independent categorical variables were performed using the chi-square test and nominal variables strength of association was obtained with Cramer's V. Different log-linear and logistic multivariate regression models were applied to observe interactions and influence of overweight or obesity-adjusted hyperuricemia and other confounding variables. Finally, a multivariate analysis of variance (MANOVA) was applied to assess the effect of hyperuricemia and overweight or obesity on changes in metabolic parameters of cardiovascular risk. A p-value $<0.05$ was taken as a statistically significant value. All analyses were performed using the SPSS program, version 21 (IBM, Armonk, NY, USA).

\section{Results}

The study population included 768 individuals, 466 women and 302 men. Average age of the study sample was $18.8 \pm 1.4$ years, and BMI was $23.6 \pm 4.4$; the somatometry results and the biochemical profile were found within reference values. The presence of central adiposity was low and only $30 \%$ of the population was overweight or obese. The least frequent metabolic alteration was hyperglycemia ( $n=20,2.6 \%$ ), while the most common was low HDL-C ( $n=295,38.5 \%)$. The prevalence of hypertension ( $n=25,3.3 \%)$, dyslipidemia $(n=44,5.7 \%$ ) and metabolic syndrome $(n=37,4.8 \%)$ was low.

When individuals with normal UA $(n=579)$ were compared with those who had hyperuricemia $(n=189)$, weight, BMI and waist circumference were observed to be higher in subjects with hyperuricemia; similarly, the metabolic profile showed higher values. The proportions of altered metabolic parameters were higher in subjects with hyperuricemia than in those who had normal UA, which indicated a statistically significant association of hyperuricemia with an increase in cardiovascular risk factors $(p<0.01)$ The strength of association allowed measuring the relationship between nominal data and, in all metabolic alterations, there was a low but statistically significant relationship with hyperuricemia: hyperglycemia, $V=0.09, p=0.008$; hypercholesterolemia, $V=0.11, p=0.003$; hypertriglyceridemia, $V=0.12, p=0.001$; low HDL-C, $\mathrm{V}=0.095, \mathrm{p}=0.008$; high LDL-C, $\mathrm{V}=0.11, \mathrm{p}=0.003$; high VLDL-C, $V=0.2, p=0.003$; hypertension, $V=0.2$, $\mathrm{p}=0.01$; mixed dyslipidemia, $\mathrm{V}=0.13, \mathrm{p}<0.0001$; metabolic syndrome, $\mathrm{V}=0.14, \mathrm{p}<0.0001$ (Table 1).

Different log-linear models were constructed to analyze the type of relationship between overweight or obesity and hyperuricemia with different metabolic parameters and cardiovascular risk factor alterations. 
Table 2. Multivariate logistic regression models for metabolic alterations and cardiovascular risk factors

\begin{tabular}{|c|c|c|c|c|c|c|}
\hline & \multicolumn{3}{|c|}{ Univariate model } & \multicolumn{3}{|c|}{ Adjusted model* } \\
\hline & OR $(95 \% \mathrm{Cl})$ & SE & p & OR (95\% Cl) & SE & $\mathrm{p}$ \\
\hline $\begin{array}{l}\text { Model for hyperglycemia } \\
\text { Hyperuricemia } \\
\text { Overweight or obesity }\end{array}$ & $\begin{array}{l}3.2(1.3-7.7) \\
1.8(1.2-2.7)\end{array}$ & $\begin{array}{l}0.46 \\
0.22\end{array}$ & $\begin{array}{l}0.01 \\
0.007\end{array}$ & $\begin{array}{l}2.7(1.1-6.9) \\
2.4(0.9-5.9)\end{array}$ & $\begin{array}{l}0.47 \\
0.46\end{array}$ & $\begin{array}{l}0.03 \\
0.06\end{array}$ \\
\hline $\begin{array}{l}\text { Model for hypercholesterolemia } \\
\text { Hyperuricemia } \\
\text { Overweight or obesity }\end{array}$ & $\begin{array}{c}1 \\
.9(1.2-3.1) \\
1.5(1.2-2.1)\end{array}$ & $\begin{array}{l}0.24 \\
0.15\end{array}$ & $\begin{array}{l}0.004 \\
0.004\end{array}$ & $\begin{array}{l}1.8(1.1-2.9) \\
1.2(0.8-1.9)\end{array}$ & $\begin{array}{l}0.24 \\
0.23\end{array}$ & $\begin{array}{c}0.01 \\
0.3\end{array}$ \\
\hline $\begin{array}{l}\text { Model for hypertriglyceridemia } \\
\text { Hyperuricemia } \\
\text { Overweight or obesity }\end{array}$ & $\begin{array}{c}1.9(1.3-2.8) \\
2(1.6-2.6)\end{array}$ & $\begin{array}{l}0.19 \\
0.22\end{array}$ & $\begin{array}{l}0.001 \\
0.0001\end{array}$ & $\begin{array}{l}1.6(1.1-2.3) \\
2.3(1.6-3.3)\end{array}$ & $\begin{array}{c}0.2 \\
0.18\end{array}$ & $\begin{array}{c}0.03 \\
0.0001\end{array}$ \\
\hline $\begin{array}{l}\text { Model for low HDL-C } \\
\text { Hyperuricemia } \\
\text { Overweight or obesity }\end{array}$ & $\begin{array}{l}1.6(1.1-2.2) \\
2.5(1.9-3.4)\end{array}$ & $\begin{array}{l}0.17 \\
0.14\end{array}$ & $\begin{array}{c}0.009 \\
0.0001\end{array}$ & $\begin{array}{l}0.9(0.7-1.4) \\
2.6(1.8-3.7)\end{array}$ & $\begin{array}{l}0.19 \\
0.18\end{array}$ & $\begin{array}{c}0.9 \\
0.0001\end{array}$ \\
\hline $\begin{array}{l}\text { Model for high LDL-C } \\
\text { Hyperuricemia } \\
\text { Overweight or obesity }\end{array}$ & $\begin{array}{l}1.8(1.2-2.5) \\
1.8(1.3-2.6)\end{array}$ & $\begin{array}{l}0.19 \\
0.17\end{array}$ & $\begin{array}{l}0.003 \\
0.001\end{array}$ & $\begin{array}{l}1.6(1.1-2.3) \\
1.5(1.1-2.2)\end{array}$ & $\begin{array}{l}0.19 \\
0.18\end{array}$ & $\begin{array}{l}0.02 \\
0.02\end{array}$ \\
\hline $\begin{array}{l}\text { Model for high VLDL-C } \\
\text { Hyperuricemia } \\
\text { Overweight or obesity }\end{array}$ & $\begin{array}{c}2.7(1.3-5.4) \\
3.9(2-7.6)\end{array}$ & $\begin{array}{l}0.35 \\
0.34\end{array}$ & $\begin{array}{l}0.004 \\
0.0001\end{array}$ & $\begin{array}{l}1.5(0.7-3.3) \\
3.8(1.9-7.6)\end{array}$ & $\begin{array}{l}0.39 \\
0.35\end{array}$ & $\begin{array}{c}0.3 \\
0.0001\end{array}$ \\
\hline $\begin{array}{l}\text { Model for hypertension } \\
\text { Hyperuricemia } \\
\text { Overweight or obesity }\end{array}$ & $\begin{array}{l}7.1(1.3-40) \\
3.1(0.6-17)\end{array}$ & $\begin{array}{l}0.89 \\
0.88\end{array}$ & $\begin{array}{c}0.03 \\
0.2\end{array}$ & $\begin{array}{l}6.8(1.1-46) \\
2.6(0.4-16)\end{array}$ & $\begin{array}{l}0.96 \\
0.91\end{array}$ & $\begin{array}{c}0.04 \\
0.3\end{array}$ \\
\hline $\begin{array}{l}\text { Model for mixed dyslipidemia } \\
\text { Hyperuricemia } \\
\text { Overweight or obesity }\end{array}$ & $\begin{array}{c}3(1.6-5.6) \\
3.2(2.1-4.9)\end{array}$ & $\begin{array}{l}0.31 \\
0.22\end{array}$ & $\begin{array}{l}0.0001 \\
0.0001\end{array}$ & $\begin{array}{l}2.5(1.3-4.7) \\
2.6(1.4-4.9)\end{array}$ & $\begin{array}{l}0.33 \\
0.32\end{array}$ & $\begin{array}{l}0.006 \\
0.003\end{array}$ \\
\hline $\begin{array}{l}\text { Model for metabolic syndrome } \\
\text { Hyperuricemia } \\
\text { Overweight or obesity }\end{array}$ & $\begin{array}{l}3.5(1.8-6.8) \\
6.7(3.7-12)\end{array}$ & $\begin{array}{l}0.34 \\
0.31\end{array}$ & $\begin{array}{l}0.0001 \\
0.0001\end{array}$ & $\begin{array}{l}2.3(1.1-4.6) \\
5.5(2.6-12)\end{array}$ & $\begin{array}{l}0.36 \\
0.38\end{array}$ & $\begin{array}{c}0.02 \\
0.0001\end{array}$ \\
\hline
\end{tabular}

The results yielded by each model indicated that hyperglycemia $(p=0.01)$, hypercholesterolemia $(p=0.005)$, hypertriglyceridemia $(p=0.01)$ low HDL-C $(p=0.0001)$, high LDL-C $(p=0.01)$, elevated VLDL-C $(p=0.04)$, hypertension $(p=0.02)$, mixed dyslipidemia $(p=0.004)$ and metabolic syndrome $(p=0.006)$ are dependent only on hyperuricemia, since the presence of overweight or obesity together with hyperuricemia did not impact on the frequencies expected for each model.

With the logistic regression models, the influence of hyperuricemia and overweight or obesity on different metabolic parameter and cardiovascular risk factor alterations was sought, but prior to applying the multivariate models, bivariate correlation analyses between UA and all metabolic parameters were performed, adjusting for the presence of hypertension, dyslipidemia, and metabolic syndrome, in order to rule out collinearity between variables. The results of the bivariate correlations indicated that there were no statistically significant correlations between variables belonging to each cardiovascular risk factor (SBP and DBP for hypertension, triglycerides and cholesterol for mixed dyslipidemia, and waist circumference, glucose, triglycerides, HDL-C, SBP and DBP for metabolic syndrome) and UA.

Different univariate and multivariate models were constructed for each metabolic alteration. In the univariate models, hyperuricemia and overweight or obesity were used. Hyperuricemia was identified, in a univariate manner, as an influence factor in all cardiovascular risk parameters, as also were overweight or obesity, except in hypertension. When the data were adjusted by gender and age, hyperuricemia was the factor with the highest influence on metabolic alterations; only in the model for low HDL-C and for high VLDL-C, this influence was not statistically significant (Table 2). 
The impact of hyperuricemia, overweight and obesity on the changes in metabolic parameters of cardiovascular risk was assessed by means of MANOVA. The results indicated that hyperuricemia alone does not significantly predict changes in the eight metabolic parameters (Wilks $\lambda=0.93, F[6,175]=2.14, p=0.05$ ), while overweight and obesity $(\mathrm{BMI}>25)$ predicts changes in all eight metabolic parameters (Wilks $\lambda=0.89, F[6,175]$ $=3.36, p=0.04)$. The interaction between hyperuricemia and overweight and obesity can significantly predict changes in all eight metabolic parameters of cardiovascular risk (Wilks $\lambda=0.91, F[6,175]=3.1, p=0.007$ ).

The $\mathrm{F}$ multivariate test indicated that the main differences between metabolic parameters in individuals with hyperuricemia were observed in SBP and DBP, and in overweight or obese individuals, in glucose, TGL, SBP and DBP. The interaction between hyperuricemia and overweight or obesity mainly affects the cholesterol, LDL-C and SBP values $(p<0.05)$.

\section{Discussion}

The sample of this study was collected over an eight-year period and obtaining a thorough medical history was necessary to determine that the individuals were apparently healthy and that therefore could be included. Although there were more women who had normal UA, the proportion of women and men who had hyperuricemia was similar. Body composition and metabolic parameters were observed to be statistically higher in subjects with hyperuricemia than in those with normal UA but, even in subjects with hyperuricemia, the values were within the reference limits. This finding is interesting because it provides evidence regarding one of the main issues around UA effects on the development of cardiovascular diseases, since many authors have suggested that it is unknown which alteration occurs first, whether cardiovascular alterations or hyperuricemia. ${ }^{13-16}$ In this study, we observed that, on average, in a population of relatively healthy young adults, there are individuals with hyperuricemia who have not yet developed metabolic alterations but have higher values than those with normal UA, which suggests, with the limitations inherent to a cross-sectional study, that subjects with hyperuricemia could develop metabolic disorders in the future.

There are different demographic (gender, ethnicity) and clinical factors (medications, comorbidities) that affect UA levels, ${ }^{17}$ and this aspect was therefore considered in the methodological design: all included subjects were of Latin-American mestizo ethnicity and referred not having any comorbidity, or chronically consuming any medication. These sample selection criteria were necessary, given that a large part of research is focused on middle-aged adults or specific patient groups, since the inclusion of adult subjects with any cardiovascular risk factor, such as hypertension, who might be using diuretic drugs such as thiazides, which induces increases in UA, cholesterol and glucose,$^{18}$ or adult populations with hyperinsulinemia, a common feature in metabolic syndrome and source of renal urate, sodium reabsorption and anti-uricosuric effects, ${ }^{19}$ involves biases that influence the interpretation of results. Therefore, we tried to control for most confounding factors of the UA-CVD interaction.

Several studies have been conducted where UA is associated with cardiovascular disease ${ }^{4,20}$ and even with death from cardiovascular events, ${ }^{21-24}$ although some of them do not demonstrate a full causal effect because they do not address causality criteria; ${ }^{24}$ in most of them, ORs or associations are indicated without reporting the strength of association. In this research, the strength of association was calculated using Cramer's V, which showed that UA has a low but statistically significant strength of association with all metabolic alterations and cardiovascular risk factors.

On the other hand, the investigations that have associated UA with any cardiovascular risk factor ${ }^{25}$ mainly point out an important univariate association, but in the adjusted models there is loss of statistical power; in addition, no analyses were found that controlled for variables' collinearity. Since a strong correlation between UA and metabolic parameters, mainly in metabolic syndrome, has been reported, ${ }^{8}$ this would indicate that, in multivariate models, where the association of UA with any cardiovascular risk factor is sought, there would be significant results thanks to the same collinearity, given that the studies are carried out in middle-aged populations where the metabolic alteration has been present for longer time in the individual. In this work, we tried to control for said collinearity with hypertension, dyslipidemia and metabolic syndrome-adjusted correlation analyses, with no previous correlation being found of the independent variable (UA) with the parameters of the response variable (hypertension, dyslipidemia, metabolic syndrome). Among the main results, we identified a dependence of all metabolic and cardiovascular risk parameters on hyperuricemia, which was not determined by overweight or obesity, both of which have been described in the genesis of any metabolic alteration and CVD. ${ }^{26}$ 
In the Mexican population, research on UA effects has been carried out mainly in children ${ }^{27}$ or adults with broad age ranges. ${ }^{28,29}$ Only one study was found in Mexican population ${ }^{30}$ that obtained similar results to those herein presented, where a high prevalence of metabolic disorders was also found in individuals with hyperuricemia, as well as higher risk of metabolic syndrome $(\mathrm{OR}=1.78,95 \% \mathrm{Cl}=1.2-2.6, \mathrm{p}=0.003)$ in those with hyperuricemia with regard to those who had normouricemia; in said study, metabolic syndrome was the only cardiovascular risk factor that was analyzed, while in this investigation, hyperuricemia was associated with several other factors and adjustment was made for different confounding variables, in addition to looking for interactions of UA with overweight and obesity for assessment of changes in metabolic parameters.

The main limitation of this study was its methodological design, since although statistical evidence suggests causal association of hyperuricemia with cardiovascular alterations, we cannot ensure that they had a chronological development subsequent to the presence of hyperuricemia; prospective observational analyses will have to be carried out to corroborate this hypothesis.

It can be concluded that hyperuricemia is significantly associated with metabolic disorders and different cardiovascular risk factors such as hypertension, mixed dyslipidemia and metabolic syndrome, an association that is independent from overweight or obesity, which reveals that hyperuricemia in young adults is a marker of a future CVD.

\section{References}

1. Organización Mundial de la Salud [sitio web]. Las 10 principales causas de defunción. Suiza: Organización Mundial de la Salud; 2018.

2. Instituto Nacional de Estadística y Geografía [sitio web]. Estadísticas vitales. Defunciones generales y fetales 2016. México: Instituto Nacional de Estadística y Geografía; 2016.

3. Liebman SE, Taylor JG, Bushinsky DA. Uric acid nephrolithiasis. Curr Rheumatol Rep. 2007;9:251-257

4. Ferreira TDS, Fernandes JFR, Araújo LDS, Nogueira LP, Leal PM, Antunes VP, et al. Serum uric acid levels are associated with cardiometabolic risk factors in healthy young and middle-aged adults. Arq Bras Cardiol. 2018;111:833-840.

5. Kanbay M, Segal M, Afsar B, Kang DH, Rodríguez-lturbe B, Johnson RJ. The role of uric acid in the pathogenesis of human cardiovascular disease. Heart. 2013;99:759-766.

6. Huang X, Cai X, Zheng W, Shen Y, Xie L. Relationship between uric acid and endothelial function in hypertensive patients with metabolic syndrome. J Clin Exp Cardiol. 2016;7:416.

7. Johnson RJ, Nakagawa T, Sánchez-Lozada LG, Shafiu M, Sundaram S, Le $M$, et al. Sugar, uric acid, and the etiology of diabetes and obesity. Diabetes. 2013;62:3307-3315.
8. Ciarla S, Struglia M, Giorgini P, Striuli R, Necozione S, Properzi G, et al. Serum uric acid levels and metabolic syndrome. Arch Physiol Biochem. 2014;120:119-122

9. Genoni G, Menegon V, Secco GG, Sonzini M, Martelli M, Castagno M, et al. Insulin resistance, serum uric acid and metabolic syndrome are linked to cardiovascular dysfunction in pediatric obesity. Int J Cardiol. 2017;249:366-371.

10. Al-Meshaweh AF, Jafar $Y$, Asem M, Akanji AO. Determinants of blood uric acid levels in a dyslipidemic Arab population. Med Princ Pract. 2012;21:209-216.

11. Baliarsingh S, Sharma N, Mukherjee R. Serum uric acid: marker for atherosclerosis as it is positively associated with "atherogenic index of plasma". Arch Physiol Biochem. 2013;119:27-31.

12. Alberti KG, Eckel RH, Grundy SM, Zimmet PZ, Cleeman JI, Donato KA, et al. Harmonizing the metabolic syndrome: a joint interim statement of the International Diabetes Federation Task Force on Epidemiology and Prevention; National Heart, Lung, and Blood Institute; American Heart Association; World Heart Federation; International Atherosclerosis Society; and International Association for the Study of Obesity. Circulation. 2009;120:1640-1645.

13. Wu AH, Gladden JD, Ahmed M, Ahmed A, Filippatos G. Relation of serum uric acid to cardiovascular disease. Int J Cardiol. 2016;213:4-7.

14. Dobson A. Is raised serum uric acid a cause of cardiovascular disease or death? Lancet. 1999;354:1578.

15. Culleton BF, Larson MG, Kannel WB, Levy D. Serum uric acid and risk for cardiovascular disease and death: the Framingham Heart Study. Ann Intern Med. 1999;131:7-13.

16. Wannamethee SG, Shaper AG, Whincup PH. Serum urate and the risk of major coronary heart disease events. Heart. 1997;78:147-153.

17. Palmer IM, Schutte AE, Huisman HW. Uric acid and the cardiovascular profile of African and Caucasian men. J Hum Hypertens. 2010;24:639-645.

18. Moser M, Feig PU. Fifty years of thiazide diuretic therapy for hypertension. Arch Intern Med. 2009;169:1851-1856.

19. Toyoki D, Shibata S, Kuribayashi-Okuma E, Xu N, Ishizawa K, Hosoyamada M, et al. Insulin stimulates uric acid reabsorption via regulating urate transporter 1 and ATP-binding cassette subfamily G member 2. Am J Physiol Renal Physiol. 2017;313:F826-F834.

20. Borghi C, Rosei EA, Bardin T, Dawson J, Dominiczak A, Kielstein JT, et al. Serum uric acid and the risk of cardiovascular and renal disease. J Hypertens. 2015;33:1729-1741

21. Magnoni M, Berteotti M, Ceriotti F, Mallia V, Vergani V, Peretto G, et al. Serum uric acid on admission predicts in-hospital mortality in patients with acute coronary syndrome. Int J Cardiol. 2017;240:25-29.

22. Ioachimescu AG, Brennan DM, Hoar BM, Hazen SL, Hoogwerf BJ. Serum uric acid is an independent predictor of all-cause mortality in patients at high risk of cardiovascular disease: a preventive cardiology information system (PreCIS) database cohort study. Arthritis Rheum. 2008;58:623-630.

23. Chen JH, Chuang SY, Chen HJ, Yeh WT, Pan WH. Serum uric acid level as an independent risk factor for all-cause, cardiovascular, and ischemic stroke mortality: a Chinese cohort study. Arthritis Rheum. 2009;61:225-232.

24. Bradford-Hill A. The environment and disease: association or causation? Proc R Soc Med. 1965;58:295-300.

25. Grayson PC, Kim SY, Lavalley M, Choi HK. Hyperuricemia and incident hypertension: a systematic review and meta-analysis. Arthritis Care Res (Hoboken). 2010;63:102-110.

26. Said S, Mukherjee D, Whayne TF. Interrelationships with metabolic syndrome, obesity and cardiovascular risk. Curr Vasc Pharmacol. 2016;14:415-425.

27. Martínez AD, Ruelas L, Granger DA. Association between body mass index and salivary uric acid among Mexican-origin infants, youth and adults: Gender and developmental differences. Dev Psychobiol. 2017;59:225-234.

28. Rubio-Guerra AF, Morales-López H, Garro-Almendaro AK, Vargas-Ayala G, Durán-Salgado MB, Huerta-Ramírez S, et al. Circulating levels of uric acid and risk for metabolic syndrome. Curr Diabetes Rev. 2017; 13:87-90.

29. Macías-Kauffer LR, Villamil-Ramírez H, León-Mimila P, Jacobo-Albavera L, Posadas-Romero C, Posadas-Sánchez R, et al. Genetic contributors to serum uric acid levels in Mexicans and their effect on premature coronary artery disease. Int J Cardiol. 2018;279:168- 173.

30. Alegría-Díaz A, Valdez-Ortiz R, Murguía-Romero M, Jiménez-Flores $R$, Villalobos-Molina R, Mummidi S, et al. Clinical significance of serum uric acid levels in Mexican young adults. Contrib Nephrol. 2018;192:125- 134. 